\title{
Definitive treatment of Graves' disease in children and adolescents
}

\author{
Aleksandra Król[1], Agnieszka Czarniecka ${ }^{\circledR 2}$, Barbara Jarząb ${ }^{\circledR 1}$ \\ ${ }^{1}$ Department of Nuclear Medicine and Endocrine Oncology, Maria Skłodowska-Curie National Research Institute of Oncology, \\ Gliwice Branch, Gliwice, Poland \\ ${ }^{2}$ The Oncologic and Reconstructive Surgery Clinic, Maria Skłodowska-Curie National Research Institute of Oncology, Gliwice \\ Branch, Gliwice, Poland
}

\begin{abstract}
Graves' disease (GD) is the most common cause of paediatric hyperthyroidism. In children and adolescents, the clinical GD course is different from that seen in adults, due to low remission rate and high prevalence of adverse events related to treatment with antithyroid drugs (ATDs). Most patients in this group require definitive therapy. As in adults, there are 2 treatment options - thyroid ablation with radioactive iodine (RAI) or surgery with preferred procedure of total thyroidectomy (TT). The choice of definitive therapy depends on many important factors such as the child's age, effectiveness of the first-line ATD treatment, presence of ATD side effects, presence of large goitre or thyroid nodules, and concomitant diseases.

The following paper provides the current guidelines on GD management in children and compares the efficacy of both definitive treatment methods as well as the acute and long-term complication rates, which must be taken into account when choosing the optimal therapeutic option. (Endokrynol Pol 2021; 72 (6): 661-665)
\end{abstract}

Key words: Graves' disease (GD); antithyroid drugs (ATDs); radioactive iodine (RAl); total thyroidectomy (TT)

\section{Introduction}

Graves' disease (GD) is an autoimmune endocrinopathy with TSH receptor antibodies (TSH-R-Ab), which imitate the TSH effect and stimulate thyroid growth and excessive hormone production. As in adults, GD is a major cause of hyperthyroidism in children and adolescents. The paediatric population constitutes only $1-5 \%$ of all patients with GD; however, it is characterized by some important distinctive features, such as much lower remission rate and higher prevalence of adverse reactions to antithyroid drugs (ATDs) [1, 2]. The majority of GD paediatric patients will ultimately require definitive therapy with radioactive iodine (RAI) or total thyroidectomy (TT). One should realize the specificity of Graves' disease in children and adolescents in order to optimize treatment outcomes.

\section{Important features of Graves' disease in children}

Graves' disease may occur at any age during childhood and has its peak during adolescence; it is much more frequent in girls than in boys. The incidence of childhood thyrotoxicosis seems to have increased in recent years [1-4]. The frequency of GD is higher when associated with coexisting autoimmune or genetic diseases, e.g. Down syndrome, Turner syndrome, or Di George syndrome, as well as in families with a history of autoimmune thyroid disorders. There are also some environmental factors regarded as potentially associated with increased risk of GD in the paediatric population: iodine excess (mandatory salt iodination), infectious diseases, selenium status, dioxins, or radiation exposure [5-10].

Clinical thyrotoxicosis in GD children is more severe than in GD adults, with tremor, palpable goitre, weight loss, muscle weakness, lack of energy, sleep disturbances, and irritability. Specific signs such as accelerated growth or increased bone age may be observed. Some disturbances such as impaired educational outcomes, subtle changes in behaviour, or anxiety may have been present for years prior to diagnosis. Some studies indicate that children and adolescents with GD are at higher risk of serious behavioural problems, and anxiety or inattention were the prominent behavioural manifestations both during the active and normalized thyroid hormone level states. Both hyperthyroidism 
and hypothyroidism (because of treatment) may result in educational and social difficulties in young patients, and this factor must be taken into account throughout the whole process of therapeutic decision making [11].

Graves' orbitopathy $(\mathrm{GO})$ is quite often seen in this population ( $38 \%$ ), especially in adolescents (11-18 years old, $68.2 \%$ ), usually mild with proptosis and soft tissue involvement as the main manifestations [12, 13].

As in adults, there are 3 treatment options for GD in children: antithyroid drugs (ATDs), radioactive iodine (RAI) ablation, and thyroidectomy. The first-line treatment for most children with GD is the use of ATDs, but the outcome of pharmacological treatment in paediatric GD patients is disappointing, with remission rates not exceeding $25-30 \%$ and a higher prevalence of adverse reactions $[14,15]$.

\section{Treatment with ATDs}

In children with GD treated with ATDs thiamazole (methimazole MMI or carbimazole CBZ, metabolized to MMI in the liver) is preferred because of its once-daily dosing regimen and rapid thyroid hormone normalization with fewer adverse events compared to propylthiouracil (PTU). PTU is associated with an unacceptable risk of side effects, especially liver failure. In the US, when PTU was initially less expensive than MMI and was used - predominantly in the 1980s, many cases of serious PTU-associated hepatic dysfunction were reported in paediatric patients.

Because safety of treatment is the priority, initial doses of ATDs in paediatric treatment are low and calculated according to the patient's weight. For mild cases the stated starting MMI dose is $0.25-0.5 \mathrm{mg} / \mathrm{kg} / \mathrm{d}$ with an upper limit of $30 \mathrm{mg} / \mathrm{d}$. If predictors of poor prognosis are present, e.g. large goitre, highly elevated pre-treatment fT4 level or TRAb level, and in severe cases with symptoms of heart failure, the starting MMI dose should be $1 \mathrm{mg} / \mathrm{kg} / \mathrm{d}$ MMI. Concomitant use of -blockers is useful for patients with severe symptoms as an initial treatment aimed at reducing tachycardia.

Majority of ATDs' adverse events occur within 3 months, so monitoring should be performed every 2 weeks during this period. The white blood count (WBC) levels of aspartate aminotransferase (AST), alanine aminotransferase (ALT), gamma-glutamyl transpeptidase (GGTP), and total bilirubin should be checked.

MMI doses are usually reduced after normalization of serum fT4 and fT3 levels, then MMI in minimal dose $(2.5-10 \mathrm{mg} / \mathrm{d})$ is continued for at least $18-24$ months in order to maintain remission. The patient is monitored every 3-4 months, so that normal thyroid function can be confirmed.
The decision to discontinue ATDs is difficult and must be made carefully. Stable TSH levels, results of TRAb level measurements, or clinical observations can be used to make such judgments. Paediatric endocrinologists are likely to continue ATD even for years, especially in younger patients ( $<15$ years old) with poor remission prognosis or in adolescent patients, with the intention of maintaining stability in the young person's school life (entrance examinations, sport activity, and so on). During adolescence the compliance may also be a particularly difficult issue.

The remission rate during long-term ATDs therapy varied from 11 to $49 \%$, even when the time of drug usage was extended to over 2 years [16-18].

In case of relapse, long-term use of low-dose ATDs (MMI or CBZ) is a possible solution. The advantages of ATD therapy include a lack radioactive iodine exposure and no surgical procedure fraught with risk of complications. On the other hand, we have permanent treatment, frequent control visits, unstable thyroid hormones levels, and the possibility of adverse drug reactions.

The decision about definitive therapy and the choice between RAI and TT depend on the patient's age, the effectiveness of first-line ATD treatment, the presence of side effects from the used drug, and certain clinical features, such as the presence of large goitre or thyroid nodules. For some children with chronic comorbidities (especially cardiac failure or diabetes) the primary definitive therapy of GD could be the best option.

\section{Radioactive iodine therapy (RAI) in children}

Properly administered RAI is a safe and reliable treatment for GD in the paediatric population, but it is still viewed as controversial by some practitioners. ${ }^{131} \mathrm{I}$ therapy should be considered in children and adolescents without remission after ATD therapy and in the case of severe adverse events due to ATDs, but it can also be used as the first-line treatment. A sufficient amount of ${ }^{131}$ I should be administered as a single dose, and the goal is to induce permanent hypothyroidism. According to American Thyroid Association and American Association of Clinical Endocrinologists (ATA/AACE) guidelines, RAI should be avoided in children younger than 5 years and is acceptable in children aged $5-10$ years if less than $10 \mathrm{mCi}$ of ${ }^{131} \mathrm{I}$ is administered. In children older than 10 years of age the activity of ${ }^{131}$ I should be more than $150 \mu \mathrm{Ci} / \mathrm{g}$ of thyroid tissue. In case of large goitre (50-80 g), higher administered activities of ${ }^{131} \mathrm{I}$ (200-300 $\mu \mathrm{Ci}$ of ${ }^{131}$ I per gram) may be needed [16, 17].

As in adults, pretreatment with ATDs is useful, with the medication being stopped 3-5 days before RAI. 
Restart of MMI after RAI is rare in children because the risk of thyroid storm in this group is low, and post-RAI treatment with methimazole is associated with an increased failure rate of RAI therapy [19-21].

At some centres a fixed dose of about $15 \mathrm{mCi}^{131} \mathrm{I}$ is administered to all children, whereas others calculate ${ }^{131}$ I activity based on gland size and 24-hour uptake. There are no data comparing outcomes of fixed versus calculated activities in children. Calculated dosing seems to help to ascertain that an adequate activity is given, and, as we know, activity $>150 \mu \mathrm{Ci}$ of ${ }^{131} \mathrm{I}$ per gram of thyroid tissue results in a hypothyroidism rate of about $95 \%$. It seems to be especially important in this group to achieve the goal in a single RAI procedure. In the case of failure, after 6 months the RAI therapy should be repeated for successful thyroid ablation. In some cases, especially in small children or in the case of non-compliance, intravenous radioactive iodine must be given. The activity should be calculated in the same way as for the orally administered one.

Radioactive iodine is excreted in saliva, urine, menstrual blood, and stool. Significant radioactivity is retained for several days within the thyroid, so children and their families must be informed about local radiation safety recommendations.

Acute side effects of RAI are rare, the most common being neck tenderness in the first week following therapy.

After RAI therapy thyroid hormones levels should be obtained every month. FT3/fT4 should be measured because TSH levels may be suppressed for several months. Typically, hypothyroidism develops in 2-3 months, and then levothyroxine treatment should be started [22-24].

Since RAI was introduced as a method of GD hyperthyroidism treatment over 70 years ago there has been concern about its potential for producing malignancies, especially leukaemias or thyroid cancer.

As we know, thyroid cancer and thyroid nodules were observed in children exposed to radiation from nuclear fallouts, but these data do not apply directly when assessing risks of RAI. The risk of thyroid cancer is higher in cases of exposure to low-level external radiation and children exposed when younger than 10 years, similarly for boys and girls, but not in cases of higher administered activities used during an RAI procedure. High doses resulted in a lowering of risk because of cell killing $[25,26]$.

Unfortunately, the retrospective long-term observations in the paediatric group are limited due to logistical difficulties in tracking patients. The data presented in Read's paper [27] show that in a cohort of 107 patients under the age of 20 years, treated with ${ }^{131}$ I between 1953 and 1973, followed for 26 years, 98 of whom were followed for 36 years, there was not a single cancer case. No malignancies were reported in Cohen's paper within a shorter post-RAI follow-up period of 2.4 years (range: 1 month-7.8 years) [28]. Nowadays a full ablation dose $>150 \mu \mathrm{Ci}$ of ${ }^{131} \mathrm{I}$ per gram of thyroid tissue is used in children, but long-term post-RAI observations in paediatric groups are still required [16].

\section{Thyroidectomy in children}

Many paediatric GD patients eventually require surgery as the definitive treatment. Total rather than partial thyroidectomy is performed to avoid the risk of relapse. Total thyroidectomy is an effective treatment for paediatric GD with a high cure rate. According to ATA/AACE guidelines, thyroidectomy is the preferred treatment for GD in young children ( $<5$ years), in cases of large thyroid gland ( $>80 \mathrm{~g}$ thyroid tissue), with significant Graves' orbitopathy signs, and in cases of malignancy suspicion [16].

The surgical complication rate is higher in children than in adults. The total number of complications is markedly higher in younger than in older children: $22 \%$ in the group $0-6$ years old and $11 \%$ in the group 13-17 years old [29].

As in the adult population, acute complications include transient hypocalcaemia, wound infection, and haematoma, while long-term complications include recurrent laryngeal nerve (RLN) injury and permanent hypoparathyroidism.

First of all, it should be emphasised that complication rates of total thyroidectomy in children, both in benign thyroid diseases and in thyroid cancer, vary depending on the surgeon's experience. Patients treated by higher-volume surgeons have significantly fewer complications than those treated by lower-volume surgeons.

Many papers demonstrate significant reduction of complication rates in paediatric patients receiving thyroidectomy from high-volume surgeons ( $>30$ thyroidectomies per year) as compared to general paediatric surgeons. [29-31]. Tuggle made cross-sectional analyses of 607 procedures ( $92 \%$ were thyroidectomies and $8 \%$ were parathyroidectomies) performed in paediatric patients by high-volume surgeons (18\%), paediatric surgeons $(21 \%)$, and others (61\%). In multivariate analyses surgeon experience was an independent predictor of complications, length of hospitalisation, and finally total cost of treatment [32]. It must be kept in mind while analysing the following data.

Hypocalcaemia is the most common complication after thyroidectomy in paediatric GD.

In Cohen's group of 30 GD children, there were six cases $(20.0 \%)$ of permanent hypoparathyroidism and 
no cases of permanent recurrent laryngeal nerve injury [28]. As reported in Hanba's paper, nearly $20 \%$ of children who underwent total thyroidectomy experienced postoperative hypocalcaemia and in $1.7 \%$ of them vocal cord paralysis was noted [33].

The reported frequency of transient hypocalcaemia ranged from 5.0 to $50.0 \%$, with a cumulative reported frequency of $22.2 \%$. Transient hypocalcaemia, which normally resolves within 6 months of thyroidectomy, can be distinguished from permanent hypoparathyroidism when long-life calcium and active vitamin D supplementation is required. Normal parathyroid function 1 year after surgery was described in most children who underwent a total thyroidectomy [34-36] with a cumulative reported permanent hypocalcaemia frequency of $2.5 \%$.

Chen et al. stated that diagnosis of GD was an independent risk factor of developing postoperative hypocalcaemia in children undergoing a thyroidectomy [37].

The second most frequently reported complication after TT in paediatric GD patients is RLN injury. Transient hoarseness may be caused by intubation, the diagnosis of transient RLN injury in children can be made on the basis of clinical signs to avoid invasive diagnostic procedures like laryngoscopy. However, laryngoscopy should be performed in each case of postoperative RLN neuropraxia if the patient suffers from long-lasting deterioration ( $>6$ months) of the voice or other clinical signs of RLN injury do not resolve after speech therapy.

When pre- and postoperative laryngoscopy or a vocal cord function test were performed in the paediatric patients who underwent thyroidectomy for GD, Machens et al. reported frequencies of transient and permanent RLN injury of 3.4 and $0.0 \%$, respectively [38]. In 22 mainly retrospective cohort studies (1424 children and adolescents) analysed by Zaat, the cumulative reported frequency of permanent RLN injury was $0.4 \%$ [34].

Other complications such as infections, haematoma, or keloid development were only rarely reported.

\section{Conclusions - how to make the right decision}

The best treatment of GD in the paediatric population is still a debatable issue. As a general rule, ATD therapy is the primary treatment option. The decision of treatment discontinuation is difficult and requires careful consideration. The choice of definitive therapy, if needed, depends on many important factors such as the child's age, effectiveness of the first-line ATD treatment, presence of ATDs side effects, presence of large goitre or thyroid nodules, and concomitant diseases.
For children younger than 5 years old long-term low-dose ATDs therapy, if well tolerated, is the treatment of choice, with surgery in exceptional cases (e.g. ATD side effects). According to American Thyroid Association and American Association of Clinical Endocrinologists (ATA/AACE) guidelines RAI should be avoided in this group.

In children aged 5-10 years ATDs are the first-line treatment and long-term, low-dose ATD therapy is a possible treatment option. Definitive treatment is needed in the case of ATD side effects. Thyroidectomy must be performed in the case of cancer risk or large goitre. RAI is acceptable in this group if the calculated required dose is less than $10 \mathrm{mCi}$ of ${ }^{131} \mathrm{I}$.

In children older than 10 years of age all of treatment methods can be used. If RAI is chosen, the activity of ${ }^{131} \mathrm{I}$ should be more than $150 \mu \mathrm{Ci} / \mathrm{g}$ of thyroid tissue.

In the teenager group, preferably up to 15 years, RAI performed as an outpatient procedure with activity of ${ }^{131} \mathrm{I}$ more than $150 \mu \mathrm{Ci} / \mathrm{g}$ of thyroid tissue is the treatment of choice.

In the case of necessary surgical treatment of GD in paediatric patients, especially in the youngest, thyroidectomy must always be performed by a high-volume surgeon. Only in such cases is thyroidectomy in paediatric patients with GD a safe procedure with a low postoperative complication rate.

Pretreatment with ATDs aim to reach the euthyroidism before surgery is needed.

RAI must be planned and performed by an experienced nuclear medicine specialist in accordance with current guidelines.

The benefits and risks of each therapy should be presented and explained to parents in the case of small children or to adolescent patients. After definitive therapy in childhood, each patient must be followed for life.

A multidisciplinary health-care team that includes an endocrinologist, an experienced thyroid surgeon, and a nuclear medicine specialist would be optimal $[16,18,19,39,40]$.

\section{Funding}

There were no grants or any other funding sources.

\section{References}

1. Vanderpump M. The epidemiology of thyroid disease. Br Med Bull. 2011; 99(1): 39-51, doi: 10.1093/bmb/ldr030.

2. Kaguelidou F, Carel JC, Léger J. Graves' disease in childhood: advances in management with antithyroid drug therapy. Horm Res. 2009; 71(6): 310-317, doi: 10.1159/000223414, indexed in Pubmed: 19506387.

3. Lavard L, Ranløv I, Perrild H, et al. Incidence of juvenile thyrotoxicosis in Denmark, 1982-1988. A nationwide study. Eur J Endocrinol. 1994; 130(6): 565-568, doi: 10.1530/eje.0.1300565, indexed in Pubmed: 8205255.

4. Rodanaki M, Lodefalk M, Forssell K, et al. The Incidence of Childhood Thyrotoxicosis Is Increasing in Both Girls and Boys in Sweden. Horm Res Paediatr. 2019; 91(3): 195-202, doi: 10.1159/000500265, indexed in Pubmed: 31096231 
5. Goday-Arno A, Cerda-Esteva M, Flores-Le-Roux JA, et al. Hyperthyroidism in a population with Down syndrome (DS). Clin Endocrinol (Oxf) 2009; 71(1): 110-114, doi: 10.1111/j.1365-2265.2008.03419.x, indexed in Pubmed: 18793345.

6. De Luca F, Corrias A, Salerno M, et al. Peculiarities of Graves' disease in children and adolescents with Down's syndrome. Eur J Endocrinol. 2010, 162(3): 591-595, doi: 10.1530/EJE-09-0751, indexed in Pubmed: 19955260

7. Wasniewska M, Corrias A, Messina MF, et al. Graves' disease prevalence in a young population with Turner syndrome. J Endocrinol Invest. 2010 33(1): 69-70, doi: 10.1007/BF03346552, indexed in Pubmed: 19542755.

8. Brown JJ, Datta V, Browning MJ, et al. Graves' disease in DiGeorge syndrome: patient report with a review of endocrine autoimmunity associated with 22q11.2 deletion. J Pediatr Endocrinol Metab. 2004; 17(11): 1575-1579, doi: 10.1515/jpem.2004.17.11.1575, indexed in Pubmed: 15570997.

9. Luo $Y$, Kawashima A, Ishido $Y$, et al. Iodine excess as an environmental risk factor for autoimmune thyroid disease. Int J Mol Sci. 2014; 15(7) 12895-12912, doi: 10.3390/ijms150712895, indexed in Pubmed: 25050783.

10. Borowiec A, Labochka D, Milczarek M, et al. Graves' disease in children in the two decades following implementation of an iodine prophylaxis programme. Cent Eur J Immunol. 2018; 43(4): 399-404, doi: 10.5114/ceji.2018.81358, indexed in Pubmed: 30799987.

11. Hamed SA, Attiah FA, Abdulhamid SK, et al. Behavioral assessment of children and adolescents with Graves' disease: A prospective study. PLoS One. 2021; 16(4): e0248937, doi: 10.1371/journal.pone.0248937, indexed in Pubmed: 33914772

12. Krassas GE, Segni M, Wiersinga WM. Childhood Graves' ophthalmopathy: results of a European questionnaire study. Eur J Endocrinol. 2005 153(4): 515-521, doi: 10.1530/eje.1.01991, indexed in Pubmed: 16189172

13. Szczapa-Jagustyn J, Gotz-Więckowska A, Kocięcki J. An update on thyroid-associated ophthalmopathy in children and adolescents. J Pediatr Endocrinol Metab. 2016; 29(10): 1115-1122, doi: 10.1515/jpem-2016-0122, indexed in Pubmed: 27682712.

14. Collen RJ, Landaw EM, Kaplan SA, et al. Remission Rates of Children and Adolescents with Thyrotoxicosis Treated with Antithyroid Drugs. Pediatrics March 1980, 65 (3) 550-556. 1980; 65(3): 550-556, indexed in Pubmed: 7360544

15. Glaser NS, Styne DM. Organization of Pediatric Endocrinologists of Northern California Collaborative Graves' Disease Study Group. Predicting the likelihood of remission in children with Graves' disease: a prospective, multicenter study. Pediatrics. 2008; 121(3): e481-e488, doi: 10.1542/peds.2007-1535, indexed in Pubmed: 18267979.

16. Bahn RS, Burch HB, Cooper DS, et al. American Thyroid Association, American Association of Clinical Endocrinologists. Hyperthyroidism and other causes of thyrotoxicosis: management guidelines of the American Thyroid Association and American Association of Clinical Endocrinologists. Endocr Pract. 2011; 17(3): 456-520, doi: 10.4158/ep.17.3.456, indexed in Pubmed: 21700562.

17. De Luca F, Valenzise M. Controversies in the pharmacological treatment of Graves' disease in children. Expert Rev Clin Pharmacol. 2018, 11(11): 1113-1121, doi: 10.1080/17512433.2018.1546576, indexed in Pubmed: 30417713.

18. Léger J, Carel JC. Arguments for the prolonged use of antithyroid drugs in children with Graves' disease. Eur J Endocrinol. 2017; 177(2): R59-R67, doi: 10.1530/EJE-16-0938, indexed in Pubmed: 28381452.

19. Rivkees SA Cornelius EA. Influence of iodine-131 dose on the outcome of hyperthyroidism in children. Pediatrics. 2003; 111(4 Pt 1): 745-749, doi: 10.1542/peds.111.4.745, indexed in Pubmed: 12671107.

20. Marcocci C, Gianchecchi D, Masini I, et al. A reappraisal of the role of methimazole and other factors on the efficacy and outcome of radioiodine therapy of Graves' hyperthyroidism. J Endocrinol Invest. 1990; 13(6): 513-520, doi: 10.1007/BF03348615, indexed in Pubmed: 2258580

21. Kadmon PM, Noto RB, Boney CM, et al. Thyroid storm in a child following radioactive iodine (RAI) therapy: a consequence of RAI versus with drawal of antithyroid medication. J Clin Endocrinol Metab. 2001; 86(5) 1865-1867, doi: 10.1210/jcem.86.5.7473, indexed in Pubmed: 11344172

22. Nebesio TD, Siddiqui AR, Pescovitz OH, et al. Time course to hypothyroidism after fixed-dose radioablation therapy of Graves' disease in children. J Pediatr. 2002; 141(1): 99-103, doi: 10.1067/mpd.2002.125494, indexed in Pubmed: 12091858.
23. Rivkees SA, Cornelius EA. Influence of iodine-131 dose on the outcome of hyperthyroidism in children. Pediatrics. 2003; 111(4 Pt 1): 745-749, doi: 10.1542/peds.111.4.745, indexed in Pubmed: 12671107.

24. West JD, Cheetham TD, Dane C, et al. Should radioiodine be the first-line treatment for paediatric Graves' disease? J Pediatr Endocrinol Metab. 2015; 28(7-8): 797-804, doi: 10.1515/jpem-2014-0176, indexed in Pubmed: 25719296.

25. Boice JD. Radiation-induced thyroid cancer--what's new? J Nat Cancer Inst. 2005; 97(10): 703-705, doi: 10.1093/jnci/dji151, indexed in Pubmed: 15900034.

26. Boice JD. Thyroid disease 60 years after Hiroshima and 20 years after Chernobyl. JAMA. 2006; 295(9): 1060-1062, doi: 10.1001/jama.295.9.1060, indexed in Pubmed: 16507808.

27. Read CH, Tansey MJ, Menda Y. A 36-year retrospective analysis of the efficacy and safety of radioactive iodine in treating young Graves' patients. J Clin Endocrinol Metab. 2004; 89(9): 4229-4233, doi: 10.1210/jc.2003-031223, indexed in Pubmed: 15356012

28. Cohen RZ, Felner EI, Heiss KF, et al. Outcomes analysis of radioactive iodine and total thyroidectomy for pediatric Graves' disease. J Pediatr Endocrinol Metab. 2016; 29(3): 319-325, doi: 10.1515/jpem-2015-0333, indexed in Pubmed: 26656610.

29. Sosa JA, Tuggle CT, Wang TS, et al. Clinical and economic outcomes of thyroid and parathyroid surgery in children. J Clin Endocrino Metab. 2008; 93(8): 3058-3065, doi: 10.1210/jc.2008-0660, indexed in Pubmed: 18522977.

30. Czarniecka A, Woźniak G, Kropińska A, et al. Surgical approach to differentiated thyroid cancers (DTC) in children [Specyfika leczenia chirurgicznego zróżnicowanych raków tarczycy (ZRT) u dzieci]. Endokrynol Pol. 2019; 70(4): 357-366, doi: 10.5603/ep.a2019.0033, indexed in Pubmed: 31489960

31. Drews JD, Cooper JN, Onwuka EA, et al. The relationships of surgeon volume and specialty with outcomes following pediatric thyroidectomy. J Pediatr Surg. 2019; 54(6): 1226-1232, doi: 10.1016/j.jpedsurg.2019.02.033, indexed in Pubmed: 30879752.

32. Tuggle CT, Roman SA, Wang TS, et al. Pediatric endocrine surgery: who is operating on our children? Surgery. 2008; 144(6): 869-77; discussion 877, doi: 10.1016/j.surg.2008.08.033, indexed in Pubmed: 19040991.

33. Hanba C, Svider PF, Siegel B, et al. Pediatric Thyroidectomy. Otolaryngol Head Neck Surg. 2017; 156(2): 360-367, doi: 10.1177/0194599816677527, indexed in Pubmed: 28145836

34. Zaat AS, Derikx JPM, Zwaveling-Soonawala N, et al. Thyroidectomy in Pediatric Patients with Graves' Disease: A Systematic Review of Postoperative Morbidity. Eur Thyroid J. 2021; 10(1):39-51, doi: 10.1159/000511345, indexed in Pubmed: 33777818

35. de Jong M, Nounou H, Rozalén García V, et al. Children are at a high risk of hypocalcaemia and hypoparathyroidism after total thyroidectomy. J Pediatr Surg. 2020; 55(7): 1260-1264, doi: 10.1016/j.jpedsurg.2019.06.027 indexed in Pubmed: 31383578.

36. Baumgarten HD, Bauer AJ, Isaza A, et al. Surgical management of pediatric thyroid disease: Complication rates after thyroidectomy at the Children's Hospital of Philadelphia high-volume Pediatric Thyroid Center. J Pediatr Surg. 2019; 54(10): 1969-1975, doi: 10.1016/j.jpedsurg.2019.02.009, indexed in Pubmed: 30902456

37. Chen Y, Masiakos PT, Gaz RD, et al. Pediatric thyroidectomy in a high volume thyroid surgery center: Risk factors for postoperative hypocalcemia. J Pediatr Surg. 2015; 50(8): 1316-1319, doi: 10.1016/j.jpedsurg.2014.10.056, indexed in Pubmed: 25783304

38. Machens A, Elwerr M, Schneider R, et al. Disease impacts more than age on operative morbidity in children with Graves' disease after total thyroidectomy. Surgery. 2018; 164(5): 993-997, doi: 10.1016/j. surg.2018.07.021, indexed in Pubmed: 30174139

39. Król A, Krajewska J, Jarzab B. Important considerations when choosing pharmacotherapy for Graves' disease in children. Expert Opin Pharmacother. 2019; 20(14): 1675-1677, doi: 10.1080/14656566.2019.1638365 , indexed in Pubmed: 31274019.

40. Wu VT, Lorenzen AW, Beck AC, et al. Comparative analysis of radioactive iodine versus thyroidectomy for definitive treatment of Graves disease. Surgery. 2017; 161(1): 147-155, doi: 10.1016/j.surg.2016.06.066, indexed in Pubmed: 27863789. 